\title{
Implementation and verification of the PMSM stator interturn short fault detection algorithm
}

\author{
Lukas Otava, Ludek Buchta \\ CEITEC - Central European Institute of Technology \\ Brno University of Technology \\ Purkynova 123, 61200 Brno, Czech Republic \\ Email: lukas.otava@ceitec.vutbr.cz, ludek.buchta@ceitec.vutbr.cz
}

\section{Acknowledgments}

This research has been supported by the project CIDAM - Center for Intelligent Drives and Advanced Machine Control TE02000103 funded by the Technology Agency of the Czech Republic.

The research was supported by ECSEL JU under the project 662192 3Ccar Integrated Components for Complexity Control in affordable electrified cars and by FEKT/FSI-J-16-3694.

\section{Keywords}

Synchronous motor, Diagnostics, Faults, Estimation technique, Microcontrollers

\begin{abstract}
This paper discusses the stator winding interturn short fault detection for three phase Permanent Magnet Synchronous Machines (PMSMs). The implementation of the Extended Kalman filter (EKF)-based fault detection algorithm is discussed. The implemented algorithm was verified with the emulated fault during different operating conditions of the drive. Measurements on a real PMSM and the implementation verification are the most important objectives of the article.
\end{abstract}

\section{Introduction}

PMSM drives are very popular due to their precision and the high power-to-weight ratio, even in very reliable applications. However, faults should be considered also in such operating conditions. The most frequent fault in PMSMs is the bearing fault, and the second most common one is the stator winding fault [i]]. Stator winding usually degrades rapidly due to a winding fault. Thus it is very important to detect a stator winding fault as soon as possible. This paper focuses especially on the interturn short fault in one phase of stator winding and considers also the open phase fault (Fig. 团).
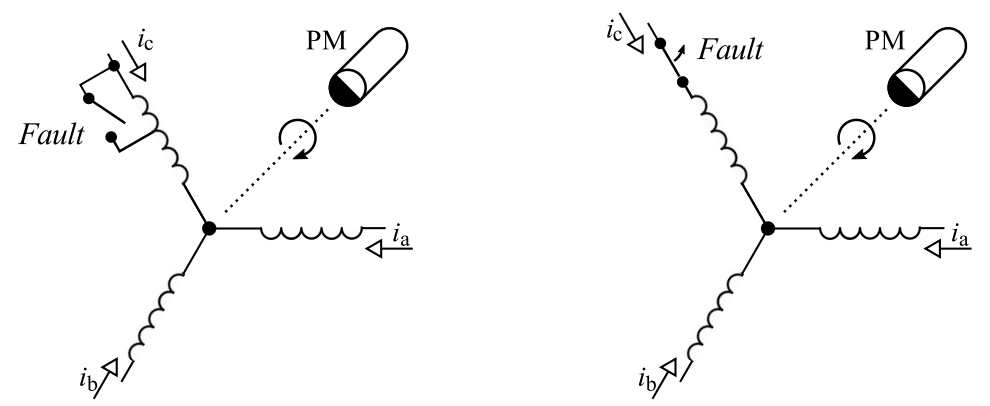

Fig. 1: Simplified schematic representing the stator winding faults 
The Kalman filter is a common tool for state estimation. There are applications of the Extended Kalman filter for parameter estimation and fault detection [2], [3], [4], [5]. Most EKF fault detections methods for PMSMs exploit two phase models (the $\alpha \beta$ or dq reference frame), but these models are not sufficient during the unbalanced stator winding situation. Therefore, the presented implementation benefits from the three phase model.

Past research utilized off-line implementation of the stator winding fault detection method. The results presented in a previous paper indicate proper functioning of the fault detection algorithm [6]. However rather limited number of experiments does not suffice for proper verification, and we thus discuss a more complex procedure to verify the implemented algorithm. A diagram of the PMSM test bench used for the given purposes is shown in Fig. [2. It can be seen, that the fault detection algorithm is integrated into the control subsystem. The implementation of the test bench is summarized in the following paragraphs. The experimental results are outlined within the conclusion.

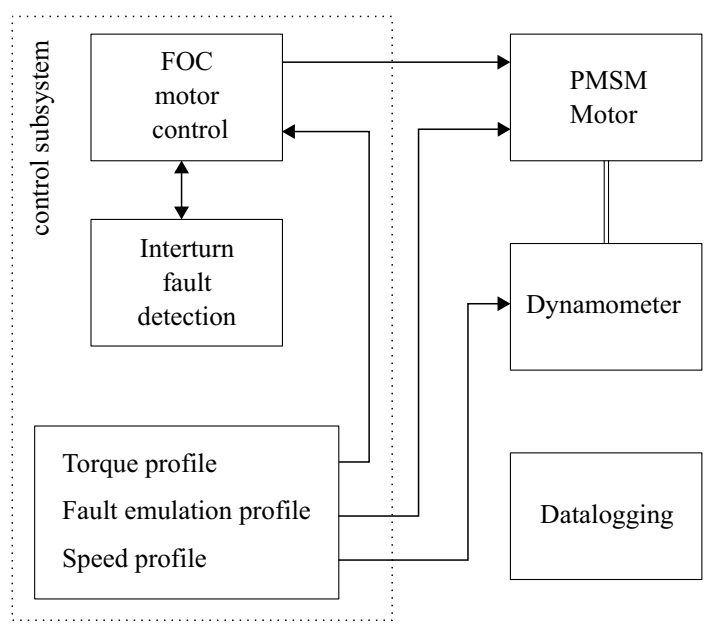

Fig. 2: The PMSM test bench

\section{Stator winding fault detection with the EKF}

The interturn short fault and the open phase fault are detected from three stator resistances, which are estimated with the Extended Kalman Filter. The open phase fault is detected if one of the estimated resistances exceeds the threshold $R_{T H}$. The interturn short fault is detected if the difference between the maximum and the minimum $\delta_{m m}$ of a fault indicator $\delta$ exceeds threshold $\delta_{T H}$. The $\delta_{m m}$ is filtered by a first order low pass filter with time constant $T_{f}$. The fault indictor $\delta$ is defined as follows:

$$
\delta=\frac{\mathbf{R}_{a b c}}{\frac{1}{3}\left(R_{a}+R_{b}+R_{c}\right)} .
$$

An diagram of the proposed fault detection strategy is in Fig. [3.

\section{PMSM stator winding model}

The model of the system is derived from the PMSM stator winding electrical equation

$$
\frac{\mathrm{d}}{\mathrm{d} t} \mathbf{i}_{a b c}=\mathbf{L}^{-1}\left(\mathbf{u}_{a b c}-\mathbf{R}_{a b c} \mathbf{i}_{a b c}-\mathbf{e}_{a b c}\right),
$$

where $\mathbf{R}_{a b c}=\operatorname{diag}\left(\left[\begin{array}{lll}R_{a} & R_{b} & R_{c}\end{array}\right]\right)$ is the resistance matrix and $\mathbf{e}_{a b c}$ is the vector of the induced electro- 


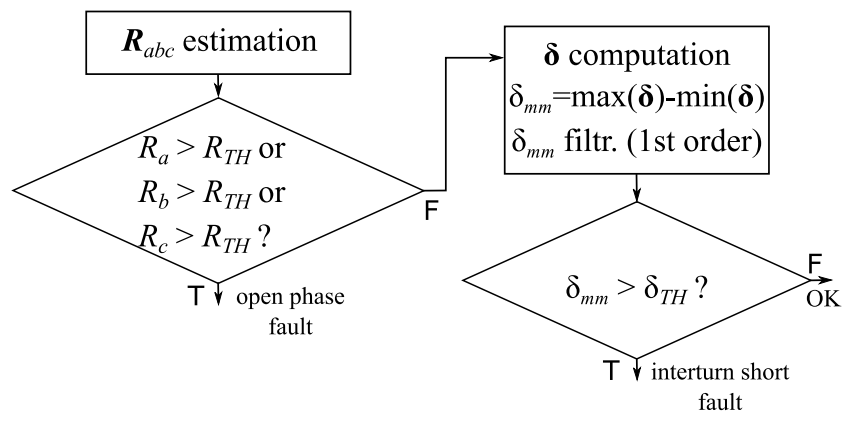

Fig. 3: The fault detection strategy

motive force voltages, which has the following form [7]:

$$
\mathbf{e}=\left[\begin{array}{c}
e_{a} \\
e_{b} \\
e_{c}
\end{array}\right]=\left[\begin{array}{c}
-\omega \psi_{m} \sin (\theta) \\
-\omega \psi_{m} \sin \left(\theta-\frac{2 \pi}{3}\right) \\
-\omega \psi_{m} \sin \left(\theta+\frac{2 \pi}{3}\right)
\end{array}\right] .
$$

The inductance matrix $\mathbf{L}$ is [7]:

$$
\mathbf{L}=\left[\begin{array}{ccc}
L_{l s}+L_{m} & -0.5 L_{m} & -0.5 L_{m} \\
-0.5 L_{m} & L_{l s}+L_{m} & -0.5 L_{m} \\
-0.5 L_{m} & -0.5 L_{m} & L_{l s}+L_{m}
\end{array}\right]
$$

Where, $L_{m}$ denotes the magnetizing inductance and $L_{l s}$ express the leakage inductance.

For the parameter estimation, the system (D) was augmented with the estimated stator resistances modeled as constant states:

$$
\frac{\mathrm{d}}{\mathrm{d} t} \mathbf{R}_{a b c}=\frac{\mathrm{d}}{\mathrm{d} t}\left[\begin{array}{l}
R_{a} \\
R_{b} \\
R_{c}
\end{array}\right]=\left[\begin{array}{l}
0 \\
0 \\
0
\end{array}\right] .
$$

The state vector of system is therefore:

$$
\hat{\mathbf{x}}=\left[\begin{array}{llllll}
i_{a} & i_{b} & i_{c} & R_{a} & R_{b} & R_{c}
\end{array}\right]^{\top} .
$$

All the motor-related parameters are in Tab. II. The continuous model of the system was discretized with the Euler method.

\section{Observability}

Before the implementation, the observability condition of the system with the state vector $\hat{\mathbf{x}}$ was verified through Lie derivative approach [8], [9] with the result that the system will be observable if the inequality $i_{a} i_{b} i_{c} \neq 0$ is satisfied. This condition was implemented in simulations, but it was experimentally verified

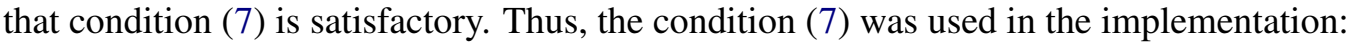

$$
\sqrt{i_{\alpha}^{2}+i_{\beta}^{2}}>\frac{I_{n}}{8} .
$$

\section{Extended Kalman Filter}

The inputs of the estimator are the rotor velocity $\omega$, rotor angle $\theta$, and phase voltages $\mathbf{u}_{a b c}$. The phase voltages are computed from the current controller outputs. The stator currents $\mathbf{i}_{a b c}$ are taken as the 
measurements of the estimator. The input vector and the measurement vector are:

$$
\mathbf{u}=\left[\begin{array}{lllll}
u_{a} & u_{b} & u_{c} & \omega & \theta
\end{array}\right]^{\top} ; \quad \mathbf{z}=\left[\begin{array}{lll}
i_{a} & i_{b} & i_{c}
\end{array}\right]^{\top} .
$$

The EKF algorithm can be generally divided into two steps [10]. Prediction step estimates state from past values according following equation

$$
\hat{\mathbf{x}}_{k}^{-}=\mathbf{f}\left(\hat{\mathbf{x}}_{k-1}, \mathbf{u}_{k}\right) .
$$

Covariance matrix prediction $\mathbf{P}_{k}^{-}$is computed according equation

$$
\mathbf{P}_{k}^{-}=\mathbf{F}_{k} \mathbf{P}_{k-1} \mathbf{F}_{k}^{\top}+\mathbf{Q}
$$

where $\mathbf{F}$ is Jacobi matrix representing the linearization of system with first element of the Taylor series.

Correction step contains Kalman gain $\mathbf{K}_{k}$ computation:

$$
\mathbf{K}_{k}=\mathbf{P}_{k}^{-} \mathbf{H}_{k}^{\top}\left(\mathbf{H}_{k} \mathbf{P}_{k}^{-} \mathbf{H}_{k}^{\top}+\mathbf{R}\right)^{-1} .
$$

where $\mathbf{H}$ is Jacobi matrix, which represents the linearization of the output function.

Then, the states are corrected according measurement residuals and Kalman gain

$$
\hat{\mathbf{x}}_{k}=\hat{\mathbf{x}}_{k}^{-}+\mathbf{K}_{k}\left(\mathbf{z}_{k}-\mathbf{g}\left(\hat{\mathbf{x}}_{k}^{-}\right)\right) .
$$

Last step of EKF algorithm is covariance matrix update

$$
\mathbf{P}_{k}=\left(\mathbf{I}-\mathbf{K}_{k} \mathbf{H}_{k}\right) \mathbf{P}_{k}^{-} .
$$

The setting of the measurement noise and the process noise covariance matrix was performed according to the current measurement noise and the requirement for estimated parameters' dynamics.

The matrix $\mathbf{Q}$ represents measurement noise. This matrix was selected according noise variance of measured currents. Function $\operatorname{diag}()$ represents square diagonal matrix with items on the main diagonal.

$$
\mathbf{Q}=\operatorname{diag}\left(\begin{array}{lll}
0.003 & 0.003 & 0.003
\end{array}\right)
$$

Matrix R represents process noise. Variance of currents were selected with lower variance than measurement noise. Estimated parameters variances were set to low value - we expect that parameters change in time very slowly.

$$
\mathbf{R}=\operatorname{diag}\left(\begin{array}{llllll}
10^{-4} & 10^{-4} & 10^{-4} & 10^{-10} & 10^{-10} & 10^{-10}
\end{array}\right)
$$

Initial conditions of $\mathbf{P}(0)$ and initial state $\hat{\mathbf{x}}(0)$ were set to high values to observe convergence of algorithm

$$
\mathbf{P}(0)=\operatorname{diag}\left(\begin{array}{llllll}
0.5 & 0.5 & 0.5 & 0.5 & 0.5 & 0.5
\end{array}\right) ; \quad \hat{\mathbf{x}}(0)=\left[\begin{array}{llllll}
0 & 0 & 0 & 0.45 & 0.45 & 0.45
\end{array}\right]^{\top}
$$

\section{Implementation}

The test bench (Fig. [2) implementation is described within this section. The hardware and software aspects of the test bench are discussed separately. 


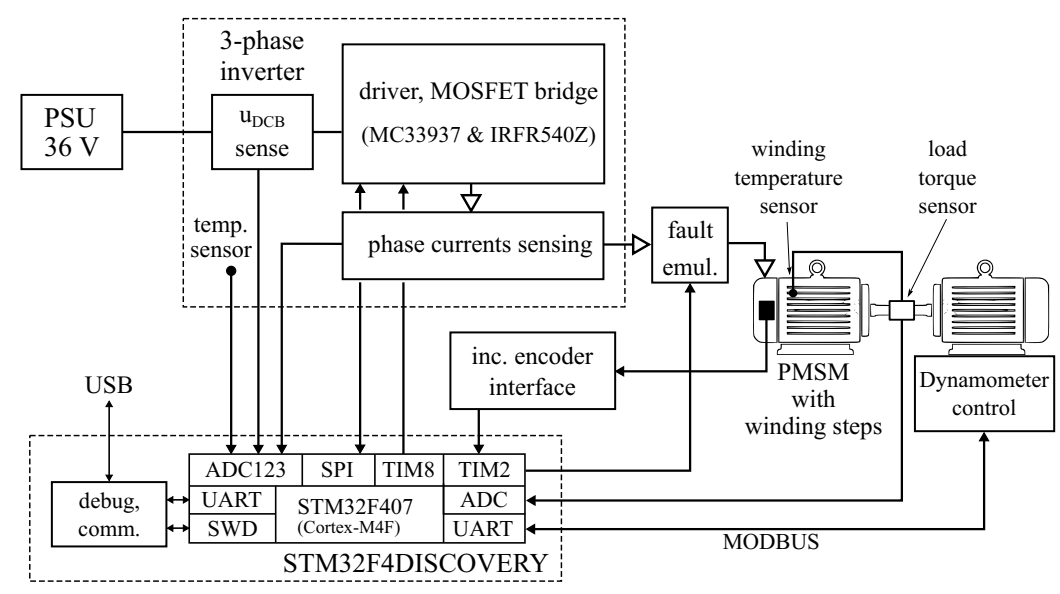

Fig. 4: The hardware configuration

\section{Hardware}

The test bench hardware can be divided into blocks, as indicated in Fig. T. The real PMSM motor is represented in Fig. [1, and its parameters are summarized in Tab. I. The PMSM, having the ability to emulate the interturn short circuit fault in one phase winding and the open phase circuit, is the key component of the test bench. The severity of interturn short fault amounts to $15 \%$. The faults can be controlled by a logic signal with an electromechanical relay. An analog temperature sensor is situated inside the stator winding.

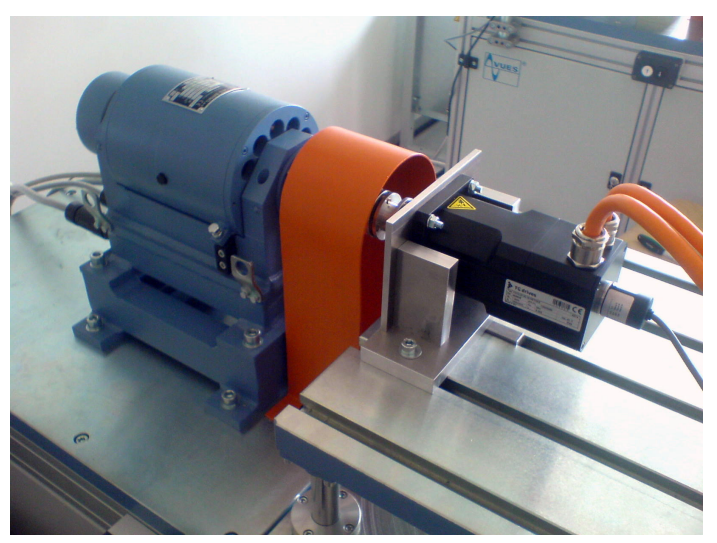

Fig. 5: PMSM connected to a dynamometer

A commercial VUES ASD 2000-2-40 dynamometer embodies the load for the PMSM. The desired torque or speed of the dynamometer is transferred from control system by the Modbus protocol over a serial line (RS-485). The measured load torque is connected to an analog-digital converter.

The motor is fed by a 3-phase low voltage inverter [11]. The inverter, together with the motor sensors, is connected to a microcontroller control system M4F microcontroller (STM32F407VGT6 by ST Microelectronics). This microcontroller is populated on an STM32F4DISCOVERY development board [12]. The microcontroller was overclocked to the $192 \mathrm{MHz}$ system clock frequency for test purposes. The configuration of the control system ensures $16 \mathrm{kHz}$ sampling rates for the motor control loop and fault detection algorithm. An 6 MBaud serial asynchronous communication link provides enough bandwidth for data recording. 
Table I: The PMSM parameters (TG drives TGT3-0130-15-36/T4KX)

\begin{tabular}{|l|c|l|}
\hline Parameter & Symbol & Value \\
\hline \hline Nominal torque & $T_{n}$ & $1.25 \mathrm{Nm}$ \\
\hline Nominal velocity & $\omega_{n}$ & $157 \mathrm{rad} \mathrm{s}^{-1}$ \\
\hline Nominal voltage & $U_{n}$ & $23 \mathrm{~V}$ \\
\hline Nominal current & $I_{n}$ & $8.55 \mathrm{~A}$ \\
\hline Permanent magnet flux & $\Psi_{m}$ & $0.0245 \mathrm{~V} \mathrm{~s}$ \\
\hline Stator resistance & $R_{s}$ & $0.5 \Omega$ \\
\hline Rotor inertia & $J$ & $0.65 \cdot 10^{-4} \mathrm{~kg} \mathrm{~m}^{2}$ \\
\hline Pole pairs & $P_{P}$ & 3 \\
\hline Magnetizing inductance & $L_{m}$ & $110 \mu \mathrm{H}$ \\
\hline Leakage inductance & $L_{l s}$ & $662 \mu \mathrm{H}$ \\
\hline
\end{tabular}

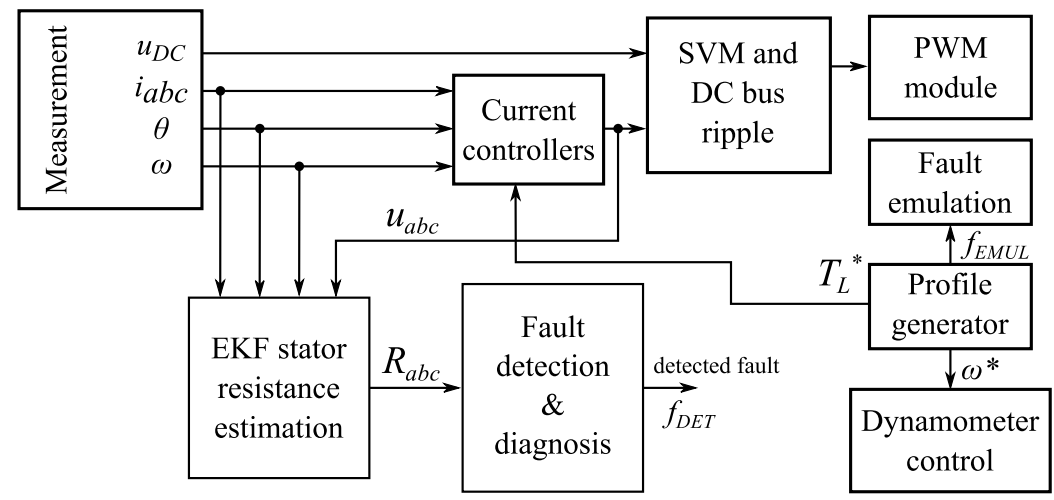

Fig. 6: The block diagram of the implemented control and fault detection algorithm

\section{Software}

The control and fault detection algorithm block diagram is introduced in Fig. 6. The implemented control system of PMSM runs with the torque reference $T_{L}^{*}$, dynamometer runs in speed control mode with the speed reference $\omega_{m}^{*}$. Both values are generated by the profile generator.

The control system software consists of microcontroller peripheral low level drivers, DSP libraries (ARM CMSIS DSP), interface to Simulink IO blocks, and a Simulink generated code for the whole control application. The IO blocks used in the Simulink model to generate the code are custom-made. The process of preparing these IO blocks includes the S-function code implementation (for a regular Simulink simulation) step and the TLC code implementation (an interface for the low level peripherals drivers) step [13]. This block diagram is implemented as a Simulink model. The C code from this model is generated with Simulink Embedded Coder. The model uses single precision floating point number representation. All sample rates employed in the model are derived from current control loop sampling rate $f_{s}=16 \mathrm{kHz}$. Finally, the complete code was compiled using a GNU GCC compiler with -O3 optimizations.

\section{Experimental results}

Three experiments are prepared to verify the implemented fault detection algorithm in the section. The interturn short fault detection was tested in two different operating conditions, in a nominal speed range on the one hand, and in an extended speed range (field weakening) on the other hand. Open phase fault detection was tested at two rotor speeds.

Experiments are prepared in a way that the desired rotor speed $\omega_{m}^{*}$ and the desired load torque $T_{L}^{*}$ change according profiles. The profiles are generated online from the nominal parameters of the PMSM (Tab. 
II) during experiment to pass through operating points with defined quantization. The generated profiles are filtered with the rate limiters. Actual rotor speed and load torque define operating point of tested PMSM. The desired speed $\omega_{m}^{*}$ was changed each 20 seconds. Each desired load torque $T_{L}^{*}$ were kept for 3 seconds. During the time specified for each operating point, the test specific fault is emulated with the $f_{E M U L}$ signal. The $T_{f}$ filter time constant was $0.1 \mathrm{~s}$ during experiments.

All three experiments used same microcontroller software just with different speed and load torque profiles. Computational time of the whole algorithm (Fig. 6) was $56 \mu$ s of $62.5 \mu$ s sampling period.
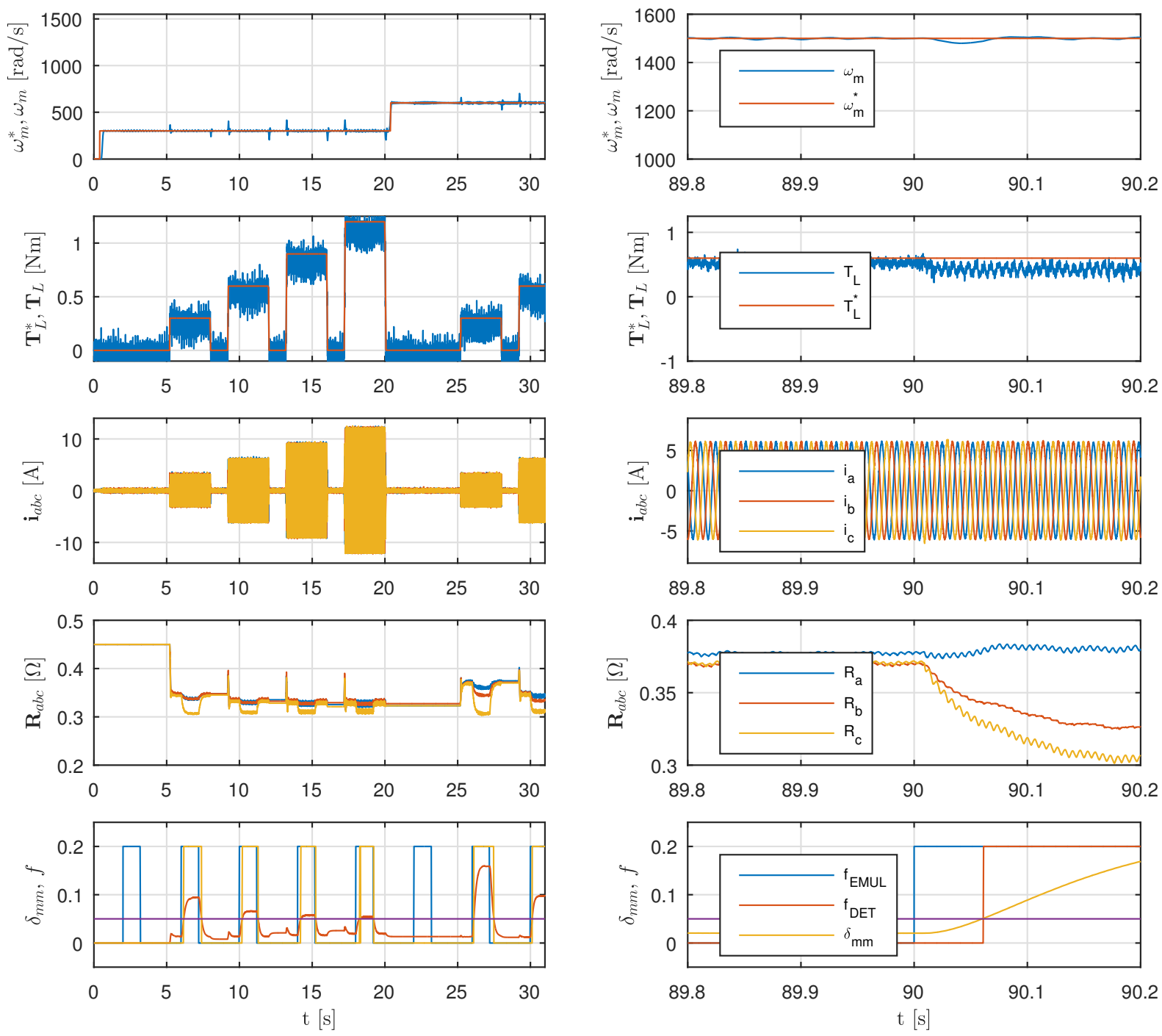

Fig. 7: The interturn short fault experiment results, nominal speed range

\section{The interturn short fault experiment during the nominal speed range}

Graphs from the interturn short fault detection experiment are in Fig. П. Desired rotor speeds $\omega_{m}^{*}$ were $\{300,600,900,1200,1500\} \mathrm{rpm}$. At this rotor speeds, the desired load torque $T_{L}^{*}$ was stepped through these values $\{0,0.3,0.6,0.9,1.2\} \mathrm{Nm}$. From presented waveforms we can notice significant relation between the $\delta_{m m}$ fault indicator and the load torque and the rotor speed. To achieve proper setting of the fault threshold $\delta_{T H}$ value, the $\delta_{m m}$ is illustrated in Fig. 8 for faulty and fault free state in different operating points. Finally, threshold value $\delta_{T H}=0.05$ was selected. The last graph in Fig. $\square$ shows, that all faults were correctly detected with loaded PMSM. However the interturn fault is not detectable if PMSM is not loaded, due to observability condition (प), as expected. 


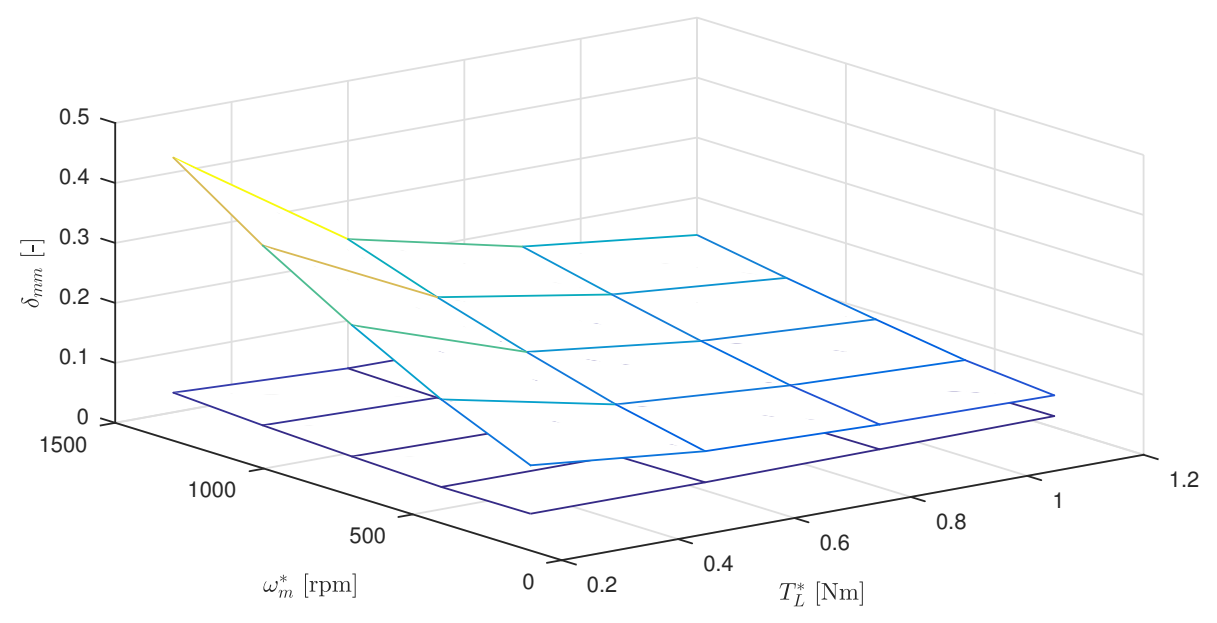

Fig. 8: The relationship of the $\delta_{m m}$ fault indicator to the rotor speed and the load torque

\section{The interturn short fault detection experiment during the extended speed range}

The interturn short fault experiment in the extended speed range, with waveforms in Fig. Q , prove similar performance results as the nominal speed range one. Rotor speed $\omega_{m}^{*}$ was $\{1800,2100,2400,2700\}$ rpm. At this rotor speeds, the load torque $T_{L}^{*}$ was stepped through these values $\{0,0.1,0.2,0.3,0.4\}$ Nm. Graphs shows, that fault indicator $\delta_{m m}$ reach higher values at higher speeds.

\section{The open phase fault detection experiment}

The open phase fault detection was tested at limited operating space. Desired rotor speed $\omega_{m}^{*}$ was $\{300,600\} \mathrm{rpm}$. At this rotor speeds, the load torque $T_{L}^{*}$ was stepped through values $\{0,0.1,0.2,0.3,0.4\}$ $\mathrm{Nm}$. The threshold $R_{T H}$ for open phase fault detection was $R_{T H}=10 R_{S}=5 \Omega$. All the important waveforms from the open phase fault detection experiment are in Fig. 10. From the stator current $1_{a b c}$ envelope we can deduce the time when the open phase fault was emulated. The steepest rise of the estimated stator resistance is consequence of emulated fault. All of the emulated faults is detected during experiment.

\section{Conclusion}

The experience with off-line fault detection gathered within previous research was incorporated in the implemented solution. The experimental results based on the verification procedure described in this paper prove the functionality of the presented fault detection algorithm and underline the key aspects for practical implementation. Generally, the authors demonstrate that the proposed, rather complex, fault detection algorithm can be run on a contemporary microcontroller without serious limitations.

\section{References}

[1] Y. Da, X. Shi, and M. Krishnamurthy, "Health monitoring, fault diagnosis and failure prognosis techniques for Brushless Permanent Magnet Machines," in 2011 IEEE Vehicle Power and Propulsion Conference. IEEE, sep 2011, pp. 1-7.

[2] R. Mocanu and A. Onea, "Phase resistance estimation and monitoring of PMSM used in electrical vehicles," in 2014 18th International Conference on System Theory, Control and Computing (ICSTCC). IEEE, oct 2014, pp. 512-519. [Online]. Available: httn: Tieeexplore.ieee.org/lndocs/enic03/wranner.htm?arnumber=6982468

[3] S.-G. Ahn, B.-G. Park, R.-Y. Kim, and D.-S. Hyun, "Fault diagnosis for open-phase faults of permanent magnet synchronous motor drives using Extended Kalman Filter," in IECON 2010 36th Annual Conference on IEEE Industrial Electronics Society. IEEE, nov 2010, pp. 835-840. [Online]. Available: http://ieeexplore.ieee.org/lpdocs/epic()3/wrapper.htm?arnumber=5675176 

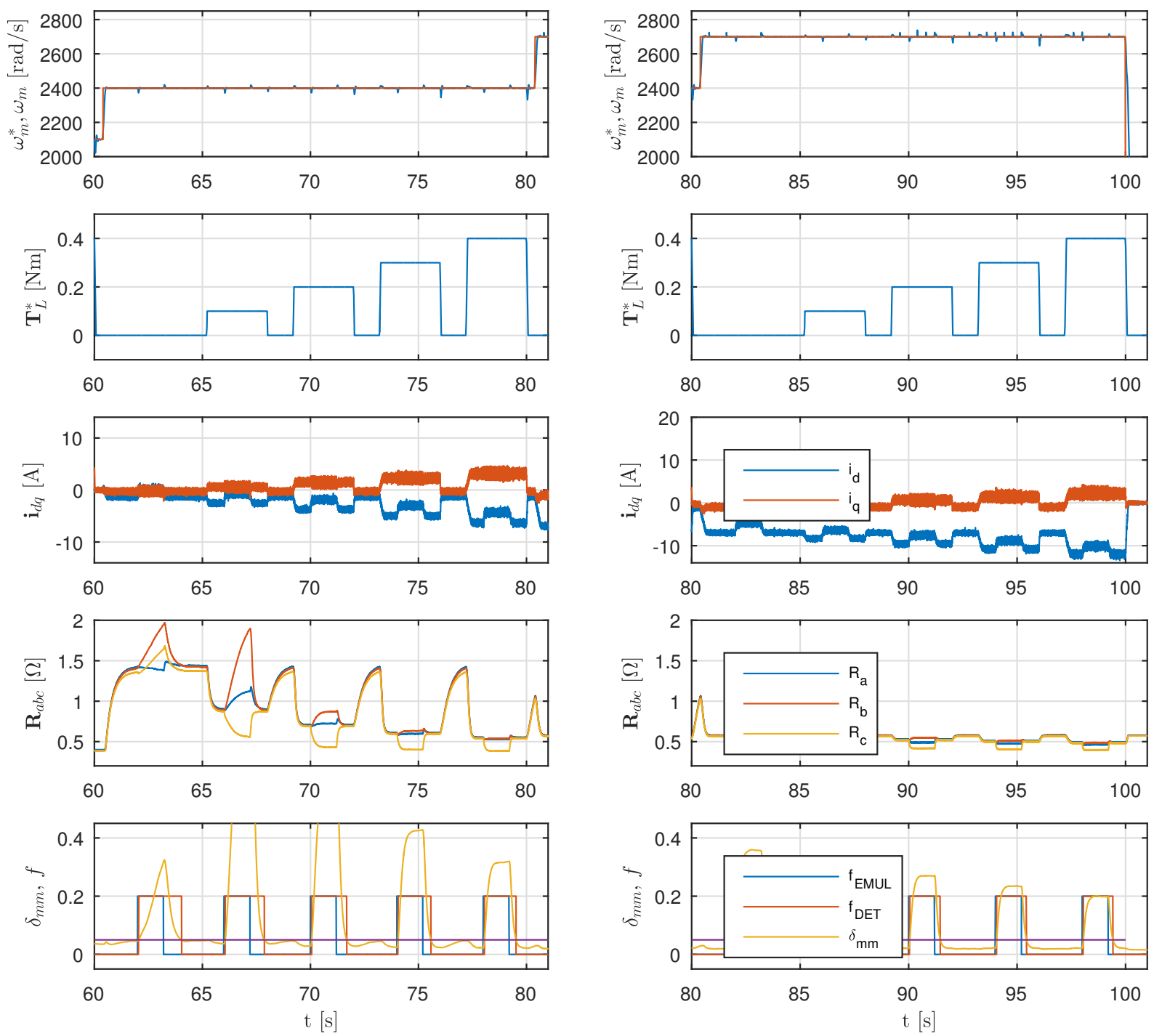

Fig. 9: The interturn short fault experiment results, extended speed range

[4] B. Aubert, J. Regnier, S. Caux, and D. Alejo, "Stator inter-turn short-circuit detection in permanent magnet synchronous generators using extended Kalman filtering," in 2013 IEEE 11th International Workshop of Electronics, Control, Measurement, Signals and their application to Mechatronics. IEEE, jun 2013, pp. 1-6. [Online]. Available: http://ieeexplore.ieee.org/document/6648943/

[5] S.-G. Ahn, B.-G. Park, R.-Y. Kim, and D.-S. Hyun, "Fault diagnosis for open-phase faults of permanent magnet synchronous motor drives using Extended Kalman Filter," in IECON 2010 36th Annual Conference on IEEE Industrial Electronics Society. IEEE, nov 2010, pp. 835-840. [Online]. Available: httn://ieeexplore ieee.org/lndocs/enic)3/wranner.htm?arnumber=5675176

[6] L. Otava and L. Buchta, "Permanent magnet synchronous motor stator winding fault detection," in IECON 2016 - 42nd Annual Conference of the IEEE Industrial Electronics Society. IEEE, oct 2016, pp. 1536-1541.

[7] S. E. Lyshevski, Electromechanical Systems, Electric Machines, and Applied Mechatronics, ser. Electric Power Engineering Series. Taylor \& Francis, 1999. [Online]. Available: http://books.google.cz/books?id=3GYUINIXKw8C 

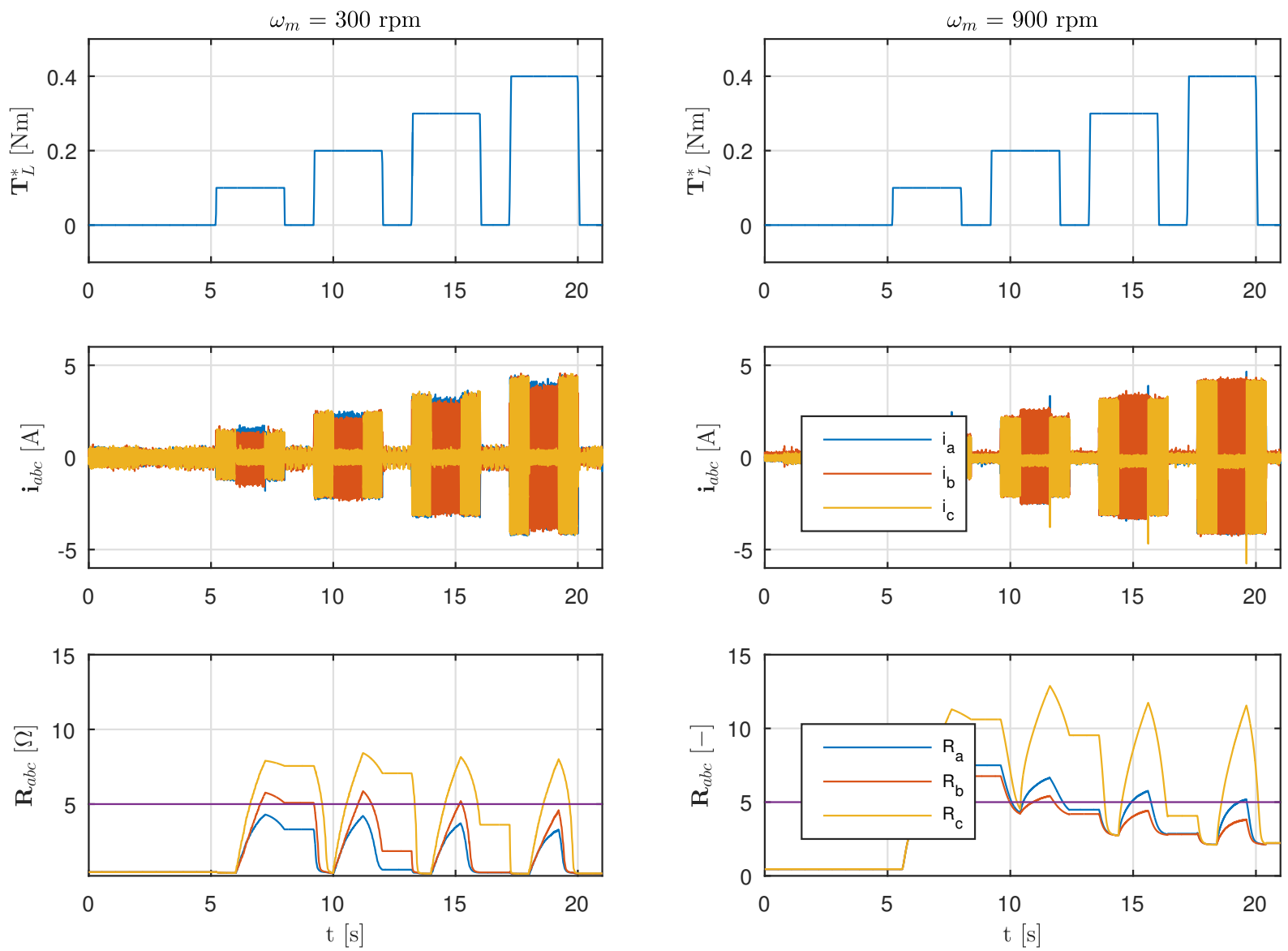

Fig. 10: The open phase fault experiment results

[8] R. Hermann and A. Krener, "Nonlinear controllability and observability," IEEE Transactions on Automatic Control, vol. 22, no. 5, pp. 728-740, oct 1977. [Online]. Available: httn://ieeexplore.ieee.org/document/1101601/

[9] P. Vaclavek and P. Blaha, "Synchronous machine drive observability analysis and sensorless control design," in 2008 IEEE 2nd International Power and Energy Conference. IEEE, dec 2008, pp. 265-270. [Online]. Available: http://ieeexplore.ieee.org/lpdocs/epic03/wrapper.htm? arnumber $=4762482$

[10] G. Welch and G. Bishop, "An Introduction to the Kalman Filter," In Practice, vol. 7, no. 1, pp. 1-16, 2006.

[11] Freescale, “3-Phase BLDC / PMSM Low Voltage Power Stage User Guide,” 2012.

[12] STMicroelectronics, “UM1472 - Discovery kit with STM32F407VG MCU,” p. 39, 2016.

[13] L. Otava, "Simulink model code generation for motor control applications," in Proceedings of the 21th Conference STUDENT EEICT 2015, Brno, 2015. 